\title{
An investigation into the food and feeding ecology of a potential aquaculture candidate, Sarotherodon galilaeus multifasciatus in a meteoritic crater lake in Ghana
}

\author{
*AMISAH, S.; AGBO, N.W. \\ Department of Fisheries and Watershed Management, Faculty of Renewable Natural Resources, Kwame Nkrumah University of Science \& \\ Technoloy, Kumasi, Ghana.e-mail steveamisah1@yahoo.co.uk
}

\begin{abstract}
An investigation into the food and feeding ecology of the cichlid, Sarotherodon galilaeus multifasciatus in a tropical meteoritic lake in Ghana was undertaken. Stomachs of the fishes, at two length classes, representing adults and juveniles, were examined and the food items identified. The juveniles of Sarotherodon galilaeus multifasciatus feed mainly on insect and insect larvae and relatively small quantities of diatoms but avoiding macrophytes. A striking feature in the composition of juvenile diet was the considerable quantities of ingested sand, which constituted about $16 \%$ of stomach contents. Ingested sand may be helpful in maceration of food in the pyloric stomach. A sandy substratum may, therefore, appear ecologically important for juveniles of the species. Adult stomachs contained mainly phytoplankton, chironomid and insect larvae with no ingested sand. No significant differences were found in the stomach contents of the fishes for the dry and wet seasons due, partly, to the lack of any considerable seasonal differences in allochthonous inputs into the lake waters. The fishes exploit a wide range of food resources in the open, sub-littoral and littoral zones of the lake. Further studies to include growth and recruitment are recommended to enhance future production of the species under culture conditions. @ JASEM
\end{abstract}

Lake Bosumtwi is a crater lake located $30 \mathrm{~km}$ south east of Kumasi at the northern tip of the Adansi mountains $06^{\circ} 30^{\prime} \mathrm{N}, 01^{\circ} 24^{\prime} \mathrm{W}$ in the forest zone of Ghana. The lake is circular in shape and has a radial drainage system. The maximum diameter and depth of the lake is estimated to be $10.5 \mathrm{~km}$ and $80 \mathrm{~km}$ respectively (Jones et al., 1985). The lake covers a total surface area of $49 \mathrm{~km}^{2}$. Studies and research have confirmed that the lake was formed as a result of a meteorite impact (Whyte, 1975; Jones et. al., 1981; Koeberl and Reimond, 1996). The lake, currently, holds 12 species of fish, all belonging to the taxonomic family of Cichlidae. Sarotherodon galilaeus multifasciatus constitutes the bulk of the cichlids captured and appears to be the most commercially exploited fish by, at least, 22 communities surrounding the lake. Investigations are considered necessary for a better understanding of the food and feeding ecology of both juvenile and adult of the species to enhance production of the species in aquaculture development.

\section{MATERIALS AND METHODS}

Fish capture and examination

A combination of sampling methods for lake fishing was employed to maximise the capture of both juvenile and adult Sarotherodon galilaeus multifasciatus. Nets of 5-mm stretched mesh were used for sampling adult and juvenile fishes. Fish capture was done twice within each month between November 2003 and October 2004 to cover the dry season (November 2003 to April, 2004) and the rainy season (May 2004 to October 2004. All fish samples were removed between 06.00 hours and 08.00 hours. In addition, ten 5-mm wire mesh traps were set up in the shallows, and trapped fishes were removed within 24-hour intervals for examination and analysis of stomach contents. Habitat and benthic substrate characteristics were noted.

\section{Analysis of stomach contents}

Fish captured were immediately identified, counted and their total lengths measured to the nearest $\mathrm{mm}$. Fish were stored under ice and rapidly transported to the laboratory for analysis. Fish lengths were categorised into two size groups of 20-49 mm Total Length (T.L) representing juvenile fish, and $50 \mathrm{~mm}$ (T.L) and over to represent adult fish. Representative samples of juvenile (329) and adult (334) fishes were dissected, guts removed and fixed in a mixture of $10 \%$ formaldehyde, glacial acetic acid and 50\% ethanol in a ratio of 5:5:90. Stomach contents and stomach fullness were examined using the Points Method (Windell and Bowen, 1978; Hyslop, 1980). In this method each food item was awarded points in relation to its estimated contribution to stomach volume. Thus points were awarded from 1 to 4 as follows: $1=1 / 4$ full stomach; $2=1 / 2$ full stomach; $3=$ $3 / 4$ full stomach; $4=$ full stomach. The percentage contribution of each food item to stomach fullness in each size class was then determined on the basis of the awarded points. Monthly mean stomach fullness was determined for juveniles and for adults to elucidate the impact of spawning and mouth brooding on feeding intensity.

\section{RESULTS AND DISCUSSION}

Sarotherodon galilaeus multifasciatus has a wide feeding range. The percentage contribution of food items to stomach fullness in juvenile and adult fishes of Sarotherodon galilaeus multifasciatus are presented (Fig. 1). There were significant differences in the stomach contents for the two length classes (Levene's test of Equality of Variances, $\mathrm{p}<0.05$ ), over the study period. 


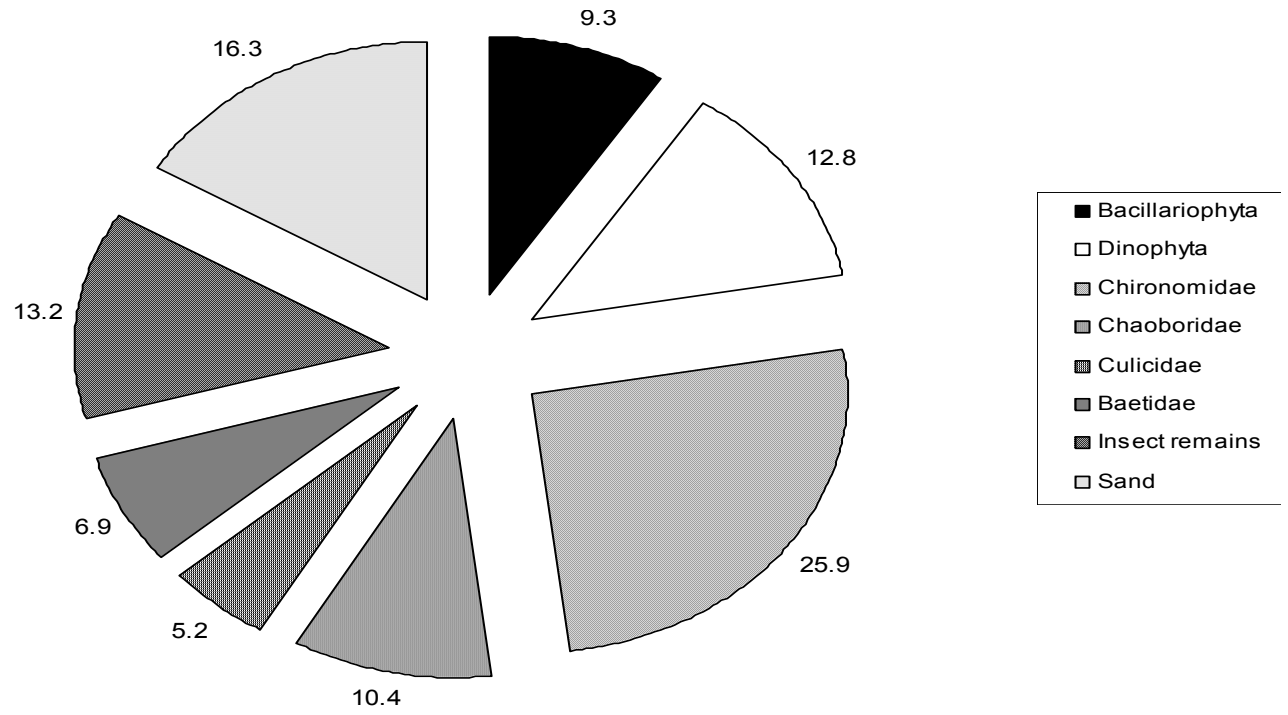

Fig 1. Percentage composition of food items in diet of juvenile Sarotherodon galilaeus multifasciatus in the lake Bosumtwi, Ghana.

Over the breeding season (November to December) the mean stomach fullness for juveniles was higher ranging from 2.5-2.9, whilst for adults the mean stomach fullness was 1.3-1.8 (Table 1). Whilst limited food items were found in the stomachs of both juvenile and adult fish, some food items were completely absent from the diets of juveniles (Figs. 1 and 2). The dinoflagellate (Peridinium sp.), the chironomid larvae, Chaoborus and some terrestrial insect parts were found in the stomachs of both juveniles and adults (Figs 1 and 2). On the other hand juvenile fishes appeared to avoid a diet of angiosperms, desmids, (mainly Scenedesmus, Cosmarium, Closterium and Dispora sp); and the Myxophyta (Anacystis sp. Anabaena sp., Oscillatoria and Calothrix sp); hence these were not found in their stomachs (Table 1). Adult fishes fed heavily on phytoplankton, insects and insect larvae, and aquatic macrophytes or angiosperms (Fig 2). Sand particles contributing up to 16.3 of stomach fullness were observed in the stomachs of juvenile fishes but were completely absent in the adult stomachs examined. (Fig.1). Mouth brooding habits are common phenomena and were observed among adult species. The practice is presumed to provide protection for the developing eggs and fry when hatched. This observation agrees with earlier studies (Trewavas, 1973; Whyte, 1975).

Table 1. Monthly mean stomach fullness of adult and juvenile Sarotherodon galilaeus multifasciatus of a meteoritic lake in Ghana

\begin{tabular}{lll}
\hline Month & Adult & Juvenile \\
\hline November & 2.0 & 2.5 \\
December & 1.7 & 2.7 \\
January & 1.6 & 2.8 \\
February & 1.7 & 2.8 \\
March & 2.5 & 2.8 \\
April & 2.9 & 2.9 \\
May & 3.0 & 2.9 \\
June & 3.1 & 2.9 \\
July & 3.1 & 2.9 \\
August & 3.1 & 3.0 \\
September & 2.9 & 3.0 \\
October & 2.4 & 3.0 \\
\hline
\end{tabular}

Points indicate: $1 .=1 / 4$ full stomach; $2=1 / 2$ full stomach; $3=3 / 4$ full stomach; 4 = Full stomach

There were significant differences in the stomach fullness of juveniles and adults (Levene's test of Equality of Variances, $p<$ $0.05)$. 

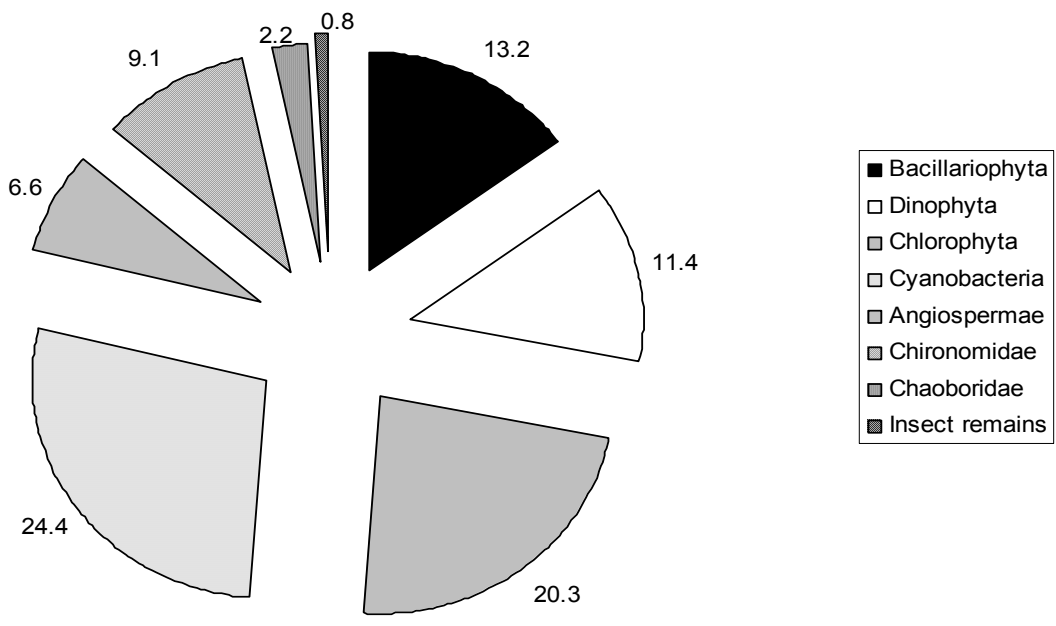

Fig 2. Percentage composition of food items in diet of adult Sarotherodon galilaeus multifasciatus in the lake Bosumtwi, Ghana.

The diversity of food organisms found in the stomachs of the Sarotherodon galilaeus multifasciatus suggests that they are euryphagous and, therefore, exploit a wide range of organisms in the lake system (Fig.2). A comparison of the food of the juvenile and adult Sarotherodon galilaeus multifasciatus shows that the two populations feed on fairly different food resources. The juveniles are insectivorous, feeding mainly on allochthonous fauna, while the adults are mainly vegetarians feeding on periphyton or phytoplankton. The change in diet with growth appears to offer a wide range of food resources to the species, whilst reducing possible competition between the adults and juveniles. The increase in the spectrum of food items used by a species in its life time would be expected to make possible the maintenance of larger populations of both adults and juveniles. Mean monthly stomach fullness in juveniles was higher during the breeding season from November to December (Table 1). This observation may be attributed to the fact that adults undergo mouth brooding at this time and this affects feeding intensity and hence reduced stomach fullness. After the breeding season the adults feed more intensively to increase stomach fullness. This needs to be taken into account in attempts to produce the species in earthen ponds. Chironomid and other insect larvae dominated the diets of juveniles (Fig.1). The dominance of chironomid larvae in the diets of juvenile species corroborates earlier studies (Whyte, 1975; Adebisi, 1981), who found that juveniles fed mainly on insect and insect larvae. Terrestrial insects and larvae (chironomids and Chaoborus) may be just small enough to be ingested by juvenile fishes while adults find additional diets in phytoplankton and the angiosperms. The absence of aquatic macrophytes, typically the angiosperms, in the stomachs of juveniles suggests that juvenile fishes feed selectively and this may be attributed to the relatively large size of macrophytes (Mayer and Wahl, 1996). A striking feature in the composition of juvenile diet was the presence of considerable quantities of ingested sand, which constituted at least $16.3 \%$ of stomach contents (Fig.1). Ingested sand particles, presumably, help in the maceration of food materials in the pyloric stomach as observed in similar studies in some African mullets ((Blaber and Whitfield, 1977; Blay, 1995). A sandy substratum appears to be a requirement for juvenile production in pond conditions. The large quantities of sand, presumably, suggest that perhaps juveniles directly or indirectly ingest sand as part of their diet. Small quantities of diatoms (bacillariophyta) were ingested by juvenile fishes. Diatoms have outer shells composed of silica. The inclusion of sand in the diets of juvenile fishes, presumably, facilitates the digestive breakdown of this food item. It further suggests that juveniles are not only surface feeders but also feed from bottom sediments. The adults, however, are primary consumers and feed mainly on phytoplankton; i.e. chlorophyta, baccillariophyta, and cyanobacteria which, in total, constituted about $60 \%$ of stomach contents (Fig.1); and might relate to the predominance of this food type and preferred particle sizes (Blaber, 1976; Blaber and Whitfield, 1977). The predominance of the cyanobacteria (blue-green algae) and the desmids (Anabaena, Cosmarium Scenedesmus and Cosmarium species also relates to the relative abundance of these species in the littoral and limnetic waters. The species show mid-water feeding habits and are, therefore, less likely to ingest sand but more phytoplankton. The dinoflagellates (Dinophyta) found in the diet are almost entirely planktonic and were quite frequently ingested by 
adults, although some juvenile fishes also fed on them. The lack of seasonal variations in the diet of the fishes may be attributed to the lack of any considerable seasonal food inputs into the lake. Juvenile and adult Sarotherodon galilaeus multifasciatus are omnivorous, feeding both on plant and animal sources to exploit a wide range of food resources in the lake. This tendency might well explain their survival, resilience despite the sustained fishing pressure on the lake

\section{REFERENCES}

Adebisi, AA. (1981). Analysis of stomach contents of the piscivorous fishes of the upper Ogun River in Nigeria. Hydrobiologia 79, 167-177.

Blaber, SJM. (1976). The food and feeding ecology of Mugilidae in the St. Lucia lake system. Biological Journal of the Linnaean Society 8, 267-277.

Blaber, SJM; Whitfield, AK (1977). The feeding ecology of juvenile mullet (Mugilidae) in southeast African estuaries. Biological Journal of the Linnaean Society 9, 277-284.

Blay, JJ. (1995). Food and feeding habits of four species of juvenile mullet (Mugilidae) in a tidal lagoon in Ghana. Journal of Fish Biology 46, 134-141.

Hyslop, EJ (1980). Stomach content analysis-a review of methods and their application. Journal of Fish Biology 17, 411-429
Jones, WB; Bacon, M; Hastings, DA (1981). The Lake Bosumtwi, Ghana Impact Crater. Geol Soc. Am. Bull 92: 342-349.

Koeberl, C; Reimold, WU. (1996). The Bosumtiw Ghana Impact Structure: Petrography and Geochemistry of Target Rocks. Meteorites and Planetary Science 31 A. 72.

Mayer, CM; Wahl, DH. (1996). The relationship between prey selectivity and growth and survival in a larval fish. Canadian Journal of Fisheries and Aquatic Sciences 54, 1504-1512.

Trewavas, E. (1973). On the cichlid fishes of the genus Pelmatochromis and Tilapia and the recognition of Sarotherodon as a distinct genus. Bulletin of the British. Museum of Natural History (Zool) 25, 1-25.

Whyte, S. A. (1975). Distribution, trophic relations and breeding habits of fish populations in a tropical lake basin (Lake Bosumtwi-Ghana) Journal of Zoology 177, 25-56.

Windell, JT; Bowen, SH. (1978). Methods for the study of fish diets based on analysis of stomach contents. In: T. Bagenal (ed). Methods for assessment of fish production in freshwaters. IBP Handbook No. 3 Blackwell Scientific Publication, Oxford, pp. 219-226. 